\title{
Overcoming SMEs Financing and Supply Chain Obstacles by Introducing Supply Chain Finance
}

\author{
Waseem Ahmed Abbasi ${ }^{1}$, Zongrun Wang ${ }^{1} \&$ Asaad Alsakarneh ${ }^{1}$ \\ ${ }^{1}$ Business School of Central South University, China \\ Correspondence: Waseem Ahmed Abbasi, Business School of Central South University, Changsha, Hunan, \\ China. E-mail: Waseem.abbasi@csu.edu.cn
}

Received: March 26, 2018

doi:10.5539/ijbm.v13n6p165
Accepted: May 4, 2018

Online Published: May 15, 2018

URL: https://doi.org/10.5539/ijbm.v13n6p165

\begin{abstract}
Keeping in view the importance of small and medium enterprises (SMEs) for the growth of a nation, we must also keep an eye on the challenges faced by those SMEs. There are various kinds of financing and supply chain options available for SMEs but they still face lot of hindrances. This paper would help us to understand why SMEs are important for the development of any country and how could we help the SMEs from facing challenges related to financing and supply chain. This study further highlights the key financing issues faced by SMEs and also focuses on major supply chain challenges confronted by the SMEs. This study put emphasis on the concept of supply chain finance (SCF) and that how SCF could help SMEs to overcome those challenges. In addition, this paper also points out the benefits and prospects of SMEs. Even though the concept of SCF is still in developing phase but it has shown significant assistance to SMEs in order to grow further.
\end{abstract}

Keywords: small and medium enterprises, supply chain management, supply chain finance, financing challenges

\section{Introduction}

The importance of small businesses in the global economy can be compared with the value of the circulatory system in the organism. SMEs play an important role for the economic growth and development of any country and are considered as the backbone of it. Usually, SMEs are the base for country's private sector. The largest chunk of employment base in many developed and developing countries belong to Small and medium enterprises (SMEs). Presently, the SMEs are not just focused only on activities associated to low-tech, ordinary, and agricultural based financial; they are also targeting other non-conventional assembling and administration areas.

The entrepreneurs who are considered as a bigger part in the economic development are usually in an inferior position because of lack of easily accessible financing from the banks and financial institutions. Additionally, mostly SME owners and entrepreneurs are not much aware of business financial issues and hence lack in combating them i.e. why they get stuck up, get bankrupt and ruin their businesses due to lack of financial discipline and business acquaintance. The major reason behind this is deficiency in inadequate availability of management \& financial advisory services that could facilitate people to run their businesses as per the best international practices. This results in ineffective utilization of deployed resources which affect the business and eventually deteriorate the overall economy.

The recent financial crisis has urged the big think-tanks to identify the other options to help the SMEs for obtaining financing which are threatened by the lack of liquidity. One of the options is supply chain finance; which is also known as supplier finance or reverse factoring. Supply chain finance improves the cash flow of businesses by allowing them to extend the payables to their suppliers while giving the choice to their large and SME suppliers to get paid early (Prime Revenue, 2018). Supply chain finance is a mode of financing that offers instant credit by enhancing the working capital for both suppliers and buyers; and embarks to diminish the risks associated with supply chain processes (Lexicon, 2018).

The competition has increased due to the globalization of supply chains. SCF is one of the choices helping organizations for keeping up their focused edge. As more organizations and establishments take part in different types of SCF with deliverable advantages, this has urged others to take an interest and has further built up the business sector for SCF administrations. The SCF practice is in expansion, it is still an emerging area for financial institutions and therefore consist of some challenges too. The information about SCF provision is not 
commonly accessible to the general public being guarded by the financial institutes for confidentiality issues. Subsequently, there is an absence of value data about the business sector size of SCF movement in various economies and it is hard to distinguish who are the key players in this field and what constitutes great practice.

Similarly, SCF at the same time is an increasingly popular area for SMEs for financing, but it is still generally immature in developing economies. Recently, there has been growing importance for this type of financing for numerous reasons. The intention of this paper is to enhance the awareness of supply chain finance as additional financing approach for SMEs that expands the access to financing. This paper highlights supply chain challenges faced by SMEs and also issues faced by SMEs while obtaining the financing. This paper further discusses how SMEs can be financed through SCF and also explain benefits and prospects of SCF scope and enablers of SCF.

\section{Literature Review}

\subsection{Importance of SMEs}

SMEs are considered as the backbone of any economy and they have the capabilities to fuel financial development as they are the base of innovation, introducing new businesses and jobs, increase the tax collection base and are drivers of advancement. SMEs improve the competition level and entrepreneurship which results in outer advantages on economy wide proficiency, development and total profitability (Beck et al, 2005). During the recent financial crisis SME sector has stayed exceptionally inventive and versatile to survive it. According to Van \& Suddle (2005) new businesses have an important role in new jobs creation. Further studies show that SMEs have contribution of average $60 \%$ of total employment in manufacturing sector in both advanced and developed economics (Ayyagari et al, 2007).

\subsection{SME Financing \& Issues}

Despite being considered that SMEs play an important role in development of economies, they always face difficulties while obtaining the financing. It is vital for SMEs that they have capacity to easily access finance for guaranteeing business achieve its development potential, subsidizing business venture and for aiding new business start-ups; an absence of funding can compel income and impede organizations' survival prospects (BIS, 2012).

It is obvious and also demonstrated by various studies that obtaining financing from banks or any other financial institution is a more prominent obstruction for SMEs than it is for large organizations, specifically in the developing countries, and that obstruction in receiving the funds unfavorably influence the development of SME area than that of substantial organizations (Schiffer and Weder, 2001; Beck et al, 2005; Beck et al, 2006).

Presently, it has become very difficult certainly for SMEs to obtain financing, specifically for new businesses and some specified sectors. It is understood that scarcity of cash could stop any business from achieving its desired production capacity. In general, SMEs are not capable enough to generate cash specifically up in the capital markets and are consequently with respect to outer sources, for the most part reliant on traditional bank financing, which itself is restricted by certain requirements because of banks' risk appetite, refinancing aptitude and capital sufficiency. As indicated by the ECB (2012a), credit conditions for SMEs are on equalization as yet fixing and access to fund has remained the second most squeezing issue for euro zone SMEs (ECB, 2012b). For SMEs in Euro zone the credit regulations are on balance still tightening and access to financing has been the second most pressing issue for them (Kraemer and Hang, 2012).

\subsection{Supply Chain Finance}

The research in area of supply chain finance is in development phase and most of the literature on SCF relates to functional level. The research on SCF is split between theoretical and business publications.

Even though the research on supply chain finance is growing, numerous research studies have been conducted on this subject, through which extraordinary advantages have been achieved. Aberdeen Group (2007) defines Supply Chain Finance (SCF) as "a combination of Trade Financing provided by a financial institution, a third-party vendor, or a corporation itself, and a technology platform that unites trading partners and financial institutions electronically and provides the financing triggers based on the occurrence of one or several supply chain events." SCF just not only focus on inter-company financing optimization, it also incorporates financing processes with clients, service providers and suppliers, which ultimately benefit all the participants to enhance their value (Christian \& Gomm, 2009).

\subsection{Supply Chain Finance and Small Medium Enterprises}

Businesses generally misjudge their capacity to extend payment terms with their suppliers. They need to focus on financing opportunities which may increase the value of the firm, and mostly SMEs don't know how working 
capital can be optimized. SCF enables SMEs' to optimize their working capital both from internal and external point of view. A lot of research is going on SCF being an alternative financing tool for SMEs and how SCF can assist SMEs to achieve their goals by optimization of working capital.

Tang (2005) used the SCF concept and discussed the different financial modes for SMEs. Guillen et al. (2007) conducted the research on short term supply chain management and found out that overall income of enterprises could be increased and could affect the operation and financing in proper supply chain management. Berger and Udell (2006) recommended some new concepts and frameworks for SME financing and primarily suggested the supply chain finance idea.

Lennart and Lars (2010) showed that in SMEs there is a strong bond between supply chain maturity and performance and besides that some bonding too between supply chain maturity and financial performance. They further indicated that SMEs can improve their performances and can attain optimistic effects on both supply chain performance and most likely also on financial performance if they use maturity indicators in the Supply Chain Operations Reference areas.

\section{Financing Obstacles Faced by SMEs}

SMEs experience significant impediments while obtaining access to loan and financing from financial institutions. Deficiency of credit facilities available to SMEs are considered as the main constraint in the development of SMEs. They depend on borrowings from friends and family and through personal savings. Cook and Nixson (2000) survey that, despite the acknowledgment of the role of SMEs in the growth development of various developing countries, SMEs improvement is constantly compelled by the restricted accessibility of financial resources to meet an assortment of operational and investment needs. SME proprietors in Europe, when gotten some information about the most essential issues they confronted, they highlight accessing finance from financial institutions in the first place, in front of issues, for example, "tax collection", absence of expertise, access to open acquisitions, unfair competition, labor law, access to the single market et cetera (European Commission Report, 2008). This section highlights the certain problems faced by SMEs while accessing the credit facilities from financial institutes.

\subsection{Lack of Financial Adequacy}

Most of the SME owners are not highly educated and thus due to lack of financial adequacy they face problems to understand the lengthy and complicated loan procedures. Around the globe financial illiteracy and intricacies is considered as a major problem for SMEs. According to Kotzè \& Smit (2008) the SME financial performance is directly related to its owner's financial abilities, if SME owners are illiterate regarding the firm's financial information, they will be unable to access different sources of credit facilities.

\subsection{Rigorous Terms \& Conditions}

The process to get loan for SMEs from financial institutes is rigorous. SME have to comply the strict terms such as; minimum 3 years of business history, tax and other banks records, business plan, high turnover, opening of new bank/credit account, credit history details, family details etc. In short FI wants to know everything about SME despite of surety to grant the loan.

\subsection{Lack of proper acceptable Collateral}

Financial institutes consider SME financing as more riskier compare to corporate lending. In order to secure them, FI demands for proper collateral to mitigate its risk. SMEs with good profitable business but not backed by adequate collateral are refused to get loan.

\subsection{Lengthy and Complicated Approval Process}

Banks are more strict while initiating the SMEs' loan applications subjecting them to cumbersome credit procedures (Kwaning et al., 2010). From applying for loan till the disbursement of credit limit, it usually takes 3 to 4 months. The procedure of credit facility approval is quite lengthy and waste much time that the projected purpose sometimes gets expired.

\subsection{High Transaction and Unhidden Costs}

Apart from lengthy and complicated approval process, there are certain costs associated with application process too, which includes; loan application charges, cost of credit worthiness report, collateral valuation fees, mortgage cost, legal charges, documentation charges etc. All these charges are extra burden on SME owners and most of the costs are not being informed to them at the time of credit application and can also be considered owners lack of financial literacy. 


\subsection{Short Maturity Period}

Usually the loans disbursed to SMEs are for short period rather than requested time. Loans disbursed to SMEs by commercial banks are normally for very short period, unable to reimburse any significant investment (Boateng, 2015).

\section{Supply Chain Challenges faced by SMEs}

Supply chain development in SME sector is at a moderately low level. In past, the SMEs' needs for supply chain were very basic; mostly focus on storage and cargo transportation with a basic purpose to cut down the logistics and distribution costs; overlooking the factor that optimized supply chain would help products to stream rapidly, steadily and securely amid each progression of the transportation procedure. Presently, SME s have started realizing the importance of supply chain development; as a fact that costs related to supply chain represents $55-65 \%$ of firm's gross revenue and now exploring the benefits of developed and executed supply chain excellence strategies which large corporate organizations have been doing from long time. Few of the major challenges faced by SMEs under supply chain are explain below:

\subsection{Lack of Coordination \& Cooperation Between Parties}

Generally, the raw material supplier of SME and its buyer are big companies; therefore, SMEs are usually stuck between larger organizations in the supply chain system. If a buyer demands some specific changes in product or increased response time and SME accepts it without knowing the capabilities of its supplier whether he can deliver it or not, damage the supply chain process and create problems. Therefore, SMEs should be careful while choosing the suppliers and should know all their business aspects.

\subsection{Potential Risk Negligence}

Being small in size, SMEs often overlook the potential risks, considering them more flexible and agile as compared to large organizations. SMEs under supply chain who don't confront risk as their top priority, are more open to face major challenges related to scalability and reaction to unstable demand. Hence, SMEs need to make robust risk mitigation strategies that highlight most common and critical supply chain related risks.

\subsection{Limited Accessible Technology}

SMEs tend to make constrained utilization of or have restricted access to innovation which can prompt a misuse of assets, poor execution, and a value-based center with poor administration which thusly influences the focused capacity of the business. Numerous SMEs depend on manual accumulation forms that are paper escalated. This makes the procedure slow, problematic and expensive. Due to manual process, SME also lacks in timely and precise information which results in invoice alienate and interrupts the incoming payments.

\subsection{Unrealistic Approaches}

SMEs usually follow unrealistic approaches; assume future sales by relying on the past sales data. In today's world nothing is sure, client needs are constantly advancing, and monstrous movements in business sector elements can hit with velocity and abruptly. Top organizations keep check on real sales as they occur so the supply chain system has the necessary data to respond rapidly to any changes in client's request. Another impractical assumption followed by SME is that supply chain will fix everything, which is not true.

\subsection{Locked Working Capital}

SMEs have the most trouble getting to bolster for working capital, even though they are the key connection in production/supply chain network. Because of having less experience and standing in market, SMEs have very less negotiation power. They have to pay in advance or quickly after the shipment to their supplier and at the same time their clients (normally big organization) demand for 30 to 90 days' payment terms. This results in locked working capital for SMEs for long period.

\section{Overcoming SMEs Financing Challenges through SCF}

SMEs have lot of probable sources of financing, includes; friends \& family, trade credit, factoring \& invoice discounting, leasing, bank financing, crowd funding etc. but in almost all of them SMEs face obstacles to get the funding. In this section, we are going to focus on how supply chain finance can overcome the financing issues faced by SMEs and also highlights the advantages and prospects of SCF.

Supply chain finance establishes a course of action between a buyer, supplier and a financial institution and it alludes to the act of arranging availability of finance by utilizing the credit standing of a buyer to enhance the working capital position of a supplier. Generally, in such courses of action include a substantial, financially sound company that purchases from numerous, financially weak SMEs and fresh start-ups, and a financial 
intermediary - generally a bank.

As we know that both buyers and suppliers are always looking for financial advantage to get from authorizing working capital; in supply chain, both parties have a deviating interest with regards to the financial transactions timings. Buyers like to pay their solicitations as late as could reasonably be expected, keeping up liquidity for as long as possible, whereas; on other hand, suppliers would like to get paid as early as possible, with a specific end goal to minimize liquidity and solvency risks.

Normally in supply chain relationships, buyer is more prevailing by a wide margin, suppliers are generally SMEs and new businesses that supply the goods to buyer are regularly paid late on their invoices. This presents a key liquidity risk to SMEs and new businesses that feel pressure while conducting a business with large buyers. Some of them can successfully mitigate the risks but others prefer not to go into a business deal with large buyers and due to that some SMEs and startup businesses can't hold up for a long, resulting in a bankruptcy and winding up their businesses.

SCF is in developing phase and is diverse from usual kind of working capital financing approaches, such as factoring and invoice discounting. In traditional methods, there is a rivalry between buyer and seller, buyer would like to have prolonged credit where as supplier wants early payment. Here SCF works very well and it enhances the collaboration between buyers and suppliers in supply chain. In SCF the finance follows the value as it moves through the supply chain network.

SCF allows both the buyer and supplier to free up their working capitals and keep up a higher level of liquidity by introducing an intermediary financial institution. It permits the buyer to hold the payment for a longer period, whereas supplier get paid earlier. We can easily say that supply chain finance is a financial agreement between buyer, seller, and a financial institution. The following picture illustrates supply chain finance process:

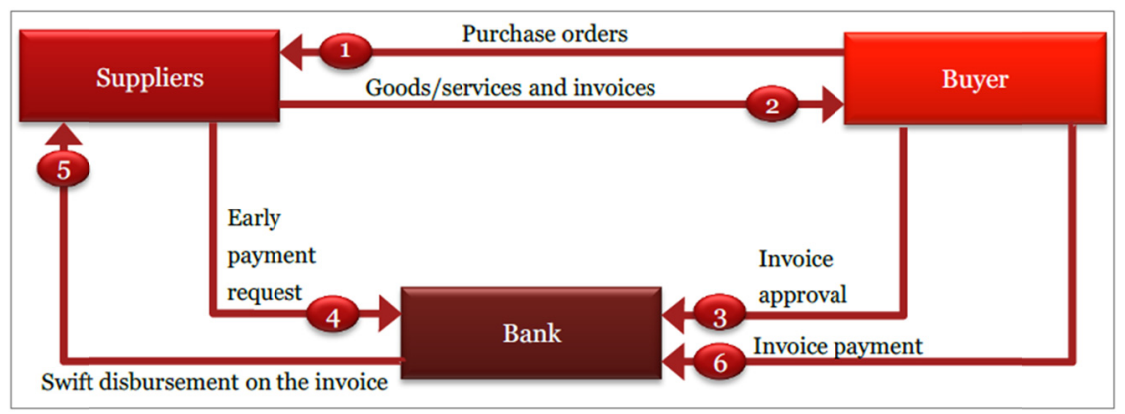

Figure 1. Supply Chain Process

Source: ( (Dervojeda, Verzijl, Nagtegaal, Lengton, \& Rouwmaat, 2014).

The Supply Chain Finance process (Figure 1) in a disentangled illustration is demonstrated where a buyer presents a request and the supplier answers with receipt and products. The buyer transfers and endorses solicitations in commonly associated IT stage, the supplier login the exchange asking for the subsidizing at a given date. The IT stage educates the bank and pays to the supplier at a pre-arranged rate and the buyer returns funds to the bank after a foreordained period. (Steeman, 2014)

For example, SME buyer with A+ credit rating, buys the goods from supplier having B+ credit rating. Supplier raise the invoice which is being approved by SME buyer. Supplier agrees to give 3 months' credit. With the help of his bank SME buyer can pay his debt within the given time period i.e. 3 months.

Though, supplier can request the buyer's bank for an early payment. If he does so buyer's bank will pay the supplier less interest and service charges. This interest is more likely to be less than the interest charged by banks in traditional financing methods such as factoring and invoice discounting. This is mainly due to using buyer's bank and also get benefit from buyer's higher credit rating as the debt is the debt of buyer, he has confirmed this by approving the invoice.

Bank will debit the SME buyer account on invoice maturity date. However, if buyer wishes to further extend the credit period, he can do so but at the cost of more interest and effects on his credit rating.

\subsection{Non-Banking Financial Institutes}

Other than banks there are large multinational groups which also offer supply chain finance product, for example: Siemens Financial, General Electric (GE) Capital. 
Such SCF products offered by giant multinational groups are specifically for chosen suppliers of that group. Being a multibank solution and a cost-efficient approach, it enables suppliers to convert their outstanding bills into non-recourse cash at a very attractive discount rate. The Supply Chain Finance Program enhances the income of chosen suppliers and upgrades their working capital. The participation amongst organization and its providers will turn out to be much more effective with the use of the SCF Program.

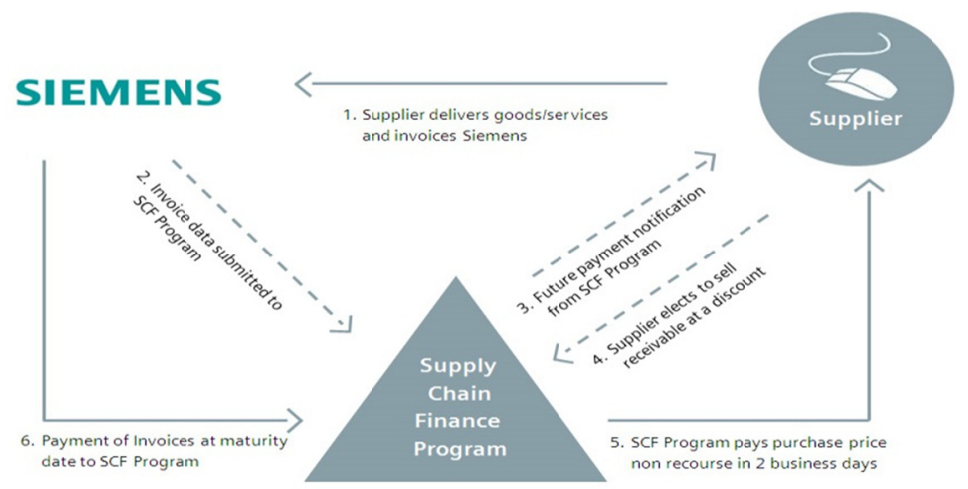

Figure 2. Supply chain finance

Source: Supply Chain Finance @ Siemens China.

The Siemens Supply Chain Finance Program empowers certain Siemens suppliers to improve their liquidity by selling their outstanding bills on Siemens at very attractive rates. Below is an example given to understand it in a more better way that how suppliers could benefit from it.

Example: A supplier deliver products worth RMB 20 million. Discount rate is cost of funds $(4 \%)+$ cost of program - fixed cost $(2.5 \%)$, total $6.5 \%$ per annum. The payment is due in 90 days net. Supplier is expecting to receive the payment within 10 days i.e. 80 days earlier when participating in the SCF Program.

\begin{tabular}{|c|c|c|}
\hline Discount rate: & $6.5 \%$ p.a. & $(2.5 \%+4 \%)$ p.a. \\
\hline Discount Charge: & RMB 288,889 & $(20 \mathrm{~m} \times 6.5 \%$ x $(80 / 360))$ \\
\hline Discounted value receivable: & RMB 19,711,111 & (Cash received by supplier) \\
\hline Cash flow benefit: & RMB 4,444,444 & $\begin{array}{l}\text { (payment after } 10 \text { days instead of } 90 \text { days) } \\
(20 \mathrm{~m} \times 80 / 360)\end{array}$ \\
\hline
\end{tabular}

\subsection{Peer-to-Peer, Solution Providers, and Marketplaces \& Hubs}

Other than banking and non-banking SCF program providers, there is a new type of 'peer-to-peer' lending operators. In this type, lending operators permit clients, especially small businesses, to obtain access to finance through a web portal. Examples are; funding circle, river rock, platform black etc.

Other key players in SCF implementation program are solution providers, these players are generally large software houses creating, specialized automation software related to payments, monetary control, workflow mobilization, for banks and other financial institutes. Being considered as close to the market's pulse, financial institutes urge their expertise, suggestions, and partnership to identify growing market opportunities, such as paper-to-digital transformation. Few large solution providers of SCF are; IBM, MISYS, Oracle, SAP, Polaris etc.

Few merchants are so driven to improve the enterprise applications and arrange such platforms that empower collaboration among all players in the SCF ecosystem, includes; clients, financial service providers and other supporting players. That platform is known as "marketplace and hub" which offer the necessary center to interconnects the frameworks of the different constituents in a 'plug-and- play' design. Few examples are; Demica, Asyx, Prime revenue, Orbian etc.

\section{Effectiveness and Benefits of SCF}

SME or start-up that necessities to hold up countless days before receiving payment on an invoice adequately has the receipt sum inaccessible to its money related operations until the receipt is settled. This negatively affects the working-capital ratio of the supplier and forces financial hazard on the supplier. In general, SME suppliers are 
smaller than their buyers in financial terms, outstanding invoices have a conversely relating bigger impact on their working-capital proportions. Thus, the impact on their liquidity is far higher as compared with bigger associations, making them more helpless against liquidity risks that originate due to late installments. Likewise, on account of their moderately small size, the risk of non-payment of an invoice for them is vigorously attached to solvency risks. As the extend of time they need to sit tight for installment draws out, so does their solvency risks.

Ultimately, SMEs and start-ups that face significant solvency risks repeatedly or over long stretches of time can face severe repercussions from their financiers, for instance through increased interest rates, fines, or - in the worst case - divestments.

\subsection{The Effectiveness of SCF}

For a strong buyer-supplier relationship and fruitful execution of SCF methods, all participants must concede to accept inventive and organized assertions; In this manner, a few contemplations must be considered:

- Willingness to go "out of the box" to decrease financial stress and increment availability to funds.

- High level of trust and comprehension amongst all the stakeholders,

- Incorporation of e-invoicing and institutionalized business detailing frameworks,

- Alignment of all business capacities to smoothen production network,

- Standardized legal and accounting techniques,

- Selecting the appropriate financial intermediary delegate. (Dervojeda, Verzijl, Nagtegaal, Lengton, and Rouwmaat, 2014)

\subsection{The Buyers and Suppliers Benefits}

The buyer trouble begins with an unfortunate working capital proportion that causes inefficiencies, poorly oversaw inventories, supply interruptions, slacking payment terms and production delays. An enhanced working capital empowers the buyer to make financial space for itself to perform. It is crucial for smoothening operational activities and development strategies, for running burden free stock administration and invoicing forms. To conclude, working capital proportions are among the center paradigm to check the organization's growth and benefit. (Dervojeda, Verzijl, Nagtegaal, Lengton, and Rouwmaat, 2014)

Unlike the LSM or multinationals, an SME supplier faces a waiting period before receiving invoice payment on an invoice successfully, this lack of funds for further financial operations creates a negative outcome on the working-capital ratio of the supplier causing financial risk on the supplier. The SME supplier's lack financial standing in comparison to their buyers, unsettled invoices have a negatively correspond to working-capital ratios, increasing their vulnerability to liquidity risks from payments delays. The risk of non-payment of financial transactions can even lead to solvency risks such as increased interest rates, penalties or bankruptcies. (Dervojeda, Verzijl, Nagtegaal, Lengton, \& Rouwmaat, 2014)

Unlikely large-scale organizations or multinationals, a SME provider faces a holding up period before getting paid on invoice effectively, this absence of funds to run operational activities smoothly makes a negative impact on the working-capital proportion of the supplier causing him financial risks. The SME supplier's faces shortage of financial standing in contrast with their buyers, disrupted invoices have an adverse effect compare to working-capital proportions, growing their vulnerability to liquidity risk from payment delays. The risk of non-payment of financial can even prompt to solvency risks, for example, increased interest rates, late payment penalties or liquidations. (Dervojeda, Verzijl, Nagtegaal, Lengton, and Rouwmaat, 2014) The benefits for supplier, buyer and bank are summarized in below table:

\begin{tabular}{lll}
\hline Buyer & Supplier & Bank \\
\hline - Improved cash flow & - Improved cash flow & - Optimized working capital \\
- Optimized working capital & - Optimized working capital & - Mitigated risks \\
- Mitigated risk & - Mitigated risk & - Reduced cost \\
- Reduced cost & - Reduced cost & - Short duration \\
- Low interest rates & - Low interest rates & - Self-liquidating financing tools \\
- Freed up credit lines & - Stable payment policy & - Expanded business volume \\
- Automated payment & - Automated payment & - Improved liquidation management \\
- Extended DSO & - Reduced DSO & - New ventures prospects \\
- Discounted price from suppliers & - Fast access to cash & - New customers opportunities \\
\hline
\end{tabular}




\begin{tabular}{lll}
\hline - Improved delivery & - Enhanced distribution network & - Additional Income from financing \\
- Lower risk on supplier innovation & - Debt free balance sheet & - Cross-selling opportunities \\
\hline
\end{tabular}

\subsection{Quantitative \& Qualitative benefits of SCF}

Practical SCF methods guarantee to essentially enhance access to funding or lessen the requirement for outside financing by creating potential liquidity from inside supply chains. There are both quantitative advantages and in addition qualitative advantages from SCF arrangements.

\begin{tabular}{l} 
Quantitative Benefits \\
\hline - Financing, liquidity and working capital reserve funds by \\
offering short term credit, improves working capital for both buyer \\
and supplier
\end{tabular}

- With enhanced competency and by decreasing financing cost, management cost could be saved.

- $\quad$ Risk cost saving through different alternatives, for example, factoring on a non-response or a constrained plan of action premise (which implies that for the SME, the risk of non-payment is exchanged or in part exchanged to the lender) or credit insurance (which implies that on account of non-installment by the SME the insurance agency pays).

\section{Qualitative Benefits}

- Improving supply chain connections by empowering cooperation amongst buyers and vendors as opposed to rivalry. In the meantime, FIs comprehend and relate better with their customers.

- Reporting advantages that come by means of mechanization of tasks that is frequently connected to SCF and which thusly profit constant precise data that upgrades enquiry and straightforwardness for all participants.

- Improving compliance value by means of authorized consistence prerequisites and additionally process mapping, risk identification, controls and detailing.

\section{Conclusion}

Doing business today is hard, and it's unlikely to get any easier. Small and midsize companies that are aware of these supply chain and financing challenges — and take proactive steps to address them — will be in a much better position to capitalize on their supply chain's and financial ability to serve existing customers better, operate more efficiently, penetrate new markets and, overall, grow more profitably. This paper has discussed all the major and key financing and supply chain challenges faced by SMEs. It also has suggested a new emerging concept of supply chain finance (SCF) and that how it could benefit SMEs in a better way to overcome those challenges. In sum, SCF has benefits for all the stakeholders in SMEs including buyers, suppliers and financial institutions.

\section{References}

Aberdeen. (2007). Working Capital Optimization: A Cross-Functional Look. Massachusetts: Aberdeen Group.

Ayyagari, M., Demirgüç-Kunt, A., \& Maksimovic, V. (2011). Firm innovation in emerging markets: the role of finance, governance, and competition. Journal of Financial and Quantitative Analysis, 46(6), 1545-1580. https://doi.org/10.1017/S0022109011000378

Beck, T., Demirgüç-Kunt, A. S. L. I., \& Maksimovic, V. (2005). Financial and legal constraints to growth: Does firm size matter? The Journal of Finance, 60(1), 137-177. https://doi.org/10.1111/j.1540-6261.2005.00727.x

Beck, T., Demirgüç-Kunt, A., Laeven, L., \& Maksimovic, V. (2006). The determinants of financing obstacles. Journal of International Money and Finance, 25(6), 932-952. https://doi.org/10.1016/j.jimonfin.2006.07.005

Berger, A. N., \& Udell, G. F. (2006). A more complete conceptual framework for SME finance. Journal of Banking \& Finance, 30(11), 2945-2966. https://doi.org/10.1016/j.jbankfin.2006.05.008

BIS, S. (2012). Access to External Finance in BIS Economics Papers. BIS, Editor.

Boateng, G. (2016). Rural banks financing of Small and Medium-Scale Enterprises (SMEs) (Doctoral dissertation).

Dervojeda, K., Verzijl, D., Nagtegaal, F., Lengton, M., \& Rouwmaat, E. (2014). Innovative Business Models: Supply chain finance. Netherlands: Business Innovation Observatory; European Union.
ECB (2012a).
The
Euro
Area
Bank
Lending
Survey. http://www.ecb.int/stats/money/surveys/lend/html/index.en.html

ECB (2012b). Survey on the access to finance of SMEs in the Euro area. http://www.ecb.int/stats/money/surveys/sme/html/index.en.html 
Guillen, G., Badell, M., \& Puigjaner, L. (2007). A holistic framework for short-term supply chain management integrating production and corporate financial planning. International Journal of Production Economics, 106(1), 288-306. DOI: https://doi.org/10.1016/j.ijpe.2006.06.008

Kotzé, L., \& Smit, A. (2008). Personal financial literacy and personal debt management: the potential relationship with new venture creation. The Southern African Journal of Entrepreneurship and Small Business Management, 1(1). https://doi.org/10.4102/sajesbm.v1i1.11

Kraemer-Eis, H., \& Lang, F. (2012). The importance of leasing for SME finance. EIF Research \& Market Analysis, WP2012/15.

Kwaning, C. O., Nyantakyi, K., \& Kyereh, B. (2015). The challenges behind smes' access to debts financing in the Ghanaian financial market. International, Journal of Small Business and Entrepreneurship Research, 3(2), 16-30.

Lennart, S., \& Lars, B. (2010). Supply chain management maturity and performance in SMEs. Operational Management Research, 3, 90-97. https://doi.org/10.1007/s12063-010-0030-6

Lexicon. (2018). Term supply chain finance. Retrieved on March 11, 2018 from http://lexicon.ft.com/Term?term=supply-chain-finance

Pfohl, H. C., \& Gomm, M. (2009). Supply chain finance: optimizing financial flows in supply chains. Logistics research, 1(3-4), 149-161. https://doi.org/10.1007/s12159-009-0020-y

Prime Revenue. (2018). What is supply chain finance. Retrieved March 11, 2018 from $\mathrm{http}: / /$ primerevenue.com/what-is-supply-chain-finance/

Schiffer, M., \& Weder, B. (2001). Firm size and the business environment: Worldwide survey results (Vol. 43). World Bank Publications

Steeman, M. (2014). The Power of Supply Chain Finance. Windesheim, 4-19.

Van Stel, A., \& Suddle, K. (2008). The impact of new firm formation on regional development in the Netherlands. Small Business Economics, 30(1), 31-47. http://dx.doi.org/10.1007/s11187-007-9054-1

\section{Copyrights}

Copyright for this article is retained by the author(s), with first publication rights granted to the journal.

This is an open-access article distributed under the terms and conditions of the Creative Commons Attribution license (http://creativecommons.org/licenses/by/4.0/). 